\title{
Correction to: The Energy-Water Nexus in Iran: The Political Economy of Energy Subsidies for Groundwater Pumping
}

Tinoush Jamali Jaghdani ${ }^{(1)}$ and

Vasyl Kvartiuk (1)

\section{Correction to:}

Chapter "The Energy-Water Nexus in Iran: The Political Economy of Energy Subsidies for Groundwater Pumping" in: S. Hülsmann and M. Jampani (eds.), A Nexus Approach for Sustainable Development, https://doi.org/10.1007/978-3-030-57530-4_16

The original version of the book was inadvertently published with an incorrect sentence in chapter "The Energy-Water Nexus in Iran: The Political Economy of Energy Subsidies for Groundwater Pumping". The sentence has been corrected now as in given below: The correction chapter and the book have been updated with changes.

From:

"Moazedi et al. (2011) have demonstrated a non-linear relationship between groundwater levels and energy use. They conclude that higher energy subsidies should be provided as groundwater levels drop. However, this recommendation does not consider the workings of Iranian politics."

To:

"Moazedi et al. (2011) have demonstrated a non-linear relationship between groundwater levels and energy use. It can be concluded from this finding that higher energy subsidies should be provided as groundwater levels drop in order to keep the same level of production." 